\section{Gabriela Bevilacqua'}

Mareni Rocha Farias',"II

Carine Raquel Blatt $t^{1,1,1,11}$

Curso de Especialização em Gestão da Assistência Farmacêutica. Curso de Farmácia. Universidade Federal de Santa Catarina (UFSC). Florianópolis, SC, Brasil

" Programa de Pós-Graduação em Farmácia. Curso de Farmácia. UFSC. Florianópolis, SC, Brasil

III Curso de Farmácia e Medicina. Universidade do Sul de Santa Catarina. Tubarão, SC, Brasil

\section{Correspondence:}

Carine Raquel Blatt

Av. José Acácio Moreira

Unisul/Curso de Farmácia, $\mathrm{n}^{\circ} 787$

Dehon

88704-900 Tubarão, SC, Brasil

E-mail: carine.blatt@unisul.br

\section{Procurement of generic medicines in a medium size municipality}

\begin{abstract}
OBJECTIVE: To analyze the financial impact of medicine procurement with the required bioavailability and or bioequivalence tests for the basic pharmaceutical services component.

METHODS: A retrospective study, based on document research of competitive bidding for medicine procurement in a medium size municipality of Santa Catarina state, Southern Brazil. Bids that occurred with (2007) and without (2008) the requirement of bioequivalence and/or bioavailability tests were analyzed. The number of resources presented by providers, the number of annual bidding processes necessary to acquire all the standard medicines, the time to finalize the bidding process, the number of failing items, the per unit cost of medicines and the total value of procurement were evaluated.
\end{abstract}

RESULTS: In 2007 and 2008 respectively, $2.6 \%$ and $56.9 \%$ of items failed. Among medicine purchases, $60.0 \%$ were increased and $29.3 \%$ decreased from 2008 to 2007 . The total procurement costs for 150 medicines, considering per unit costs and average annual consumption was R\$2,288,120.00 (2007) and $\mathrm{R} \$ 4,270,425.00$ (2008).

CONCLUSIONS: The requirement for bioequivalence and/or bioavailability tests increased costs by more than $100 \%$ for the basic pharmaceutical services component. There is a need to discuss Generic Medicine Policies to agree with Pharmaceutical Assistance Policies and the National Essential Medicines Report.

DESCRIPTORS: Drugs, Generic. Therapeutic Equivalency. Biological Availability. Competitive Bidding. Pharmaceutical Services, economics.

\section{INTRODUCTION}

Although decentralization of health services in the public sector began in 1990, until 1997 the process to procure medicines followed a centralized management model, performed by the Medications Center (CEME). The termination of this body in connection with the National Medications Policy published in $1998^{6}$ reinforced the decentralization policy proposed by the Sistema Único de Saúde (SUS - National Unified Health System) and transferred management ${ }^{9}$ of pharmaceutical services to municipalities. According to Kornis ${ }^{6}$ management and financing problems combined with sourcing logistics became great challenges in pharmaceutical services.

Procurement of medications in the public sector is performed through a bidding process, with competition between participants. Considering the finite resources, the challenge for public sector managers is to plan the medicines procurement process so that product quality in not diminished by the need to save money. ${ }^{8}$ 
Besides transferring responsibility for performing medicines procurement to states and municipalities, the National Medicines Policy ${ }^{6}$ has also adopted the registration and use of generic medicines as a priority.

Generic medications are defined as products similar to the innovator medicines, which are interchangeable and designated by the Brazilian Nonproprietary Name (BNN) and the International Nonproprietary Name (INN). ${ }^{a}$ They are usually produced after the expiration or renunciation of patent protection or other exclusivity right, once efficacy, safety and quality are proven.

The Generic Medicines Policy (GMP) has been considered both nationally and internationally as a strategy to decrease costs and promote access to medicines. ${ }^{3,4,5,16}$ In Brazil, the substitutability of the innovator medicine with generic medications is assured by pharmaceutical equivalence and bioequivalence tests performed by laboratories credentialed by the Agênica Nacional de Vigilância Sanitária (ANVISA - National Health Surveillance Agency). Quality is assured by monitoring production facilities as well as through GMP, in accordance with RDC No. 210/ANVISA ${ }^{12}$

ANVISA requires evidence of therapeutic equivalence of all oral medication prescribed by doctors, through demonstration of bioequivalence through relative bioavailability tests in vivo. For non-oral medications and non-prescription oral medications, therapeutic equivalence is proven by in vitro test for pharmaceutical equivalence. ${ }^{13}$

A study evaluating regulatory trends of generic medications in 14 Latin American and Caribbean countries described the most common regulatory aspects of generic medication policy. It is mandatory to use the INN on labels (in 13 of 14 countries), make public sector prescriptions with the INN (12 of 14) and undertake public sector procurement processes with the INN (11 of 14).$^{15}$ Brazil fulfills these criteria and also establishes preference for generic medicines in public purchases, when prices and other procurement conditions are equal, and requires ANVISA to periodically edit the list of generics registered in the country.

Nonetheless, these measures appear insufficient to guarantee the availability of generics in public facilities, since usually brand name similar medicines are acquired rather than the generic or innovator medicines. According to a study by Miranda et al, in different regions of Brazil, only $25 \%$ of medications available in the public services studied were generic. ${ }^{11}$

Different explanations for the predominance of the brand name similar medicines in public purchases may include problems in fulfilling the legislation, lack of interest by generic providers to participate in public purchases and offer of better prices for brand name similar medications. ${ }^{13}$ What differentiates the generics from the brand name similar medicines is bioequivalence with the innovator medicines and not good manufacturing practices or intrinsic quality, which are required for all medications. ${ }^{6}$

The brand name similar medicines existed before the Generics Law and are copies, which beginning in May 2003 should assimilate as generics by presenting the same tests when renewing registration. ${ }^{6}$ Therefore, medications produced from November 2009 should prove pharmaceutical equivalence (in vitro test), and antibiotics, antineoplastic, and oral antiretrovirals should pass a relative bioavailability test (in vivo). By October 2014, all additional oral use therapeutic medicines classes will have passed the same tests. ${ }^{13}$

Even given these changes, similar medications are viewed with skepticism by managers, health professionals and patients. Studies performed in Brazil show quality problems in part of these medications. Batistic et al ${ }^{1}$ compiled data on physical analysis and quality of ferrous sulfate pills and oral solutions over a period of four years and found $37 \%$ of samples discordant with quality specifications, including labeling nonconformity, grade of the principal active ingredient (above or below declared), average weight, cracks in the pills and presence of precipitate in solutions. Another study ${ }^{2}$ evaluated the quality of $10 \mathrm{mg}$ enalapril and $40 \mathrm{mg}$ propranolol pills procured by a bidding process and distributed in the public health network of a municipality in Santa Catarina state, Southern Brazil, for a one year period, and found that five of seven lots had quality problems.

In the municipality investigated, in 2008, following extensive discussion between managers and health professionals about the National Medicines Policy, the National Pharmaceutical Services Policy, the National Generics Policy and in spite of doubts of the quality of brand name similar medicines, a procurement of medicines occurred, which required that products had tests for bioequivalence and/or bioavailability. The study aimed to analyze the financial impact of medicines procurement with the requirement of bioavailability and/or bioequivalence tests for the basic pharmaceutical services component.

\section{METHODS}

A retrospective study based on document research of the bidding processes for medicine procurement undertaken by the Municipal Health Secretary of a medium size municipality in Santa Catarina state.

a Lei Federal n. 9.787, de 10 de fevereiro de 1999. Altera a Lei nº. 6.360, de 26 de setembro de 1976, que dispõe sobre a vigilância sanitária, estabelece o medicamento genérico, dispõe sobre a utilização de nomes genéricos em produtos farmacêuticos e dá outras providências. Diario Oficial Uniao. 11 fev 1999:1. 
The municipality has approximately 170,000 inhabitants and a list of medicines for basic pharmaceutical services component consisting of 171 items in 2007, increased to 195 items in 2008 . The procurement modality utilized in both years was an open auction with price registration.

The Pharmaceutical Services coordinators participated in the development of the solicitation, technical analysis of proposals and medication receipt. The legal and financial requirements of the bidding, as well as the execution of the auction were the responsibility of purchasing sector of the Municipal Health Secretary, together with the sector responsible for bidding in the Municipal Administration Secretary. The schedule for medicine procurement was made for 12 months, and the bidding process performed in the first trimester. When the solicited items could not be procured, a new bidding process was undertaken, and this was repeated until all items were acquired.

The year 2007 was chosen because medicine procurement was performed without the bioavailability and/ or bioequivalence tests required in 2008, and both years were compared. Analysis included number of bids made by providers, number of annual bidding processes necessary to acquire all standard medicines, time to finalize the bidding process, the proportion of uncounted (failed) items, per unit cost and total value of procurement.

Per unit cost of medicines and quantity acquired were collected. The proportion of items that increased and decreased in cost and the average percent differences were determined from the difference in per unit cost of each medication procured in the two years of analysis.

The total financial impact of generic procurement was evaluated through projected average annual consumption and per unit cost of each medication in the years analyzed. When more than one bidding process was used to procure the same medication, the per unit cost was calculated by averaging the values. Non-generic medicines procured in 2008 were excluded from analysis.

The total cost analysis included medications procured in 2007 and in the first two auctions of 2008 , for generic or innovator medicines, a total of 150 medicines. The 2007 monetary values were adjusted according to the General Price Index - Internal FGV Availability (GPI-IA)

\section{RESULTS}

Seven auction processes were performed: three in 2007 and four in 2008. In the first auction in 2007, $2.6 \%$ of items failed, while in the first auction of 2008 the percentage was $56.9 \%$ (Table). After failing in two procurement attempts in 2008 , with the requirement of generics, the Health Department opted for procurement without the generics requirement in order to not compromise medicine availability. It took seven months to finalize the auction process on both years.

Even before the first auction in 2008, a pharmaceutical laboratory officially registered opposition to the rules and requested reconsideration of the requirement to present bioavailability and bioequivalence tests, and this was the only request related to the technical requirements described in the acts for auction.

The changes in per unit costs are stratified by increase, decrease and without change from 2007 to 2008 are presented in Figure 1.

Of the 150 items analyzed, 90 had increased per unit costs in 2008. The mean increase of per unit costs was $246.98 \%$ (Standard deviation - SD: 4.58). The greatest difference found was for fenobarbital $100 \mathrm{mg}$, procured for $\mathrm{R} \$ 0.03$ per pill in 2007 and $\mathrm{R} \$ 0.88$ in 2008 , a difference of $3,163 \%$. In 2008, 44 items had lower prices compared to 2007 . The greatest difference between prices was $34.0 \%$, with mean of $12.7 \%$ (SD: 0.09). Per unit price of the other medicines did not change between 2008 and 2007. In 2007, procurement of 150 medicines cost $R \$ 2,288,120.00$. In 2008 , the same quantity of the same medicines cost R\$ $4,270,425.00$, which corresponds to an increase of approximately $87 \%$ (Figure 2).

\section{DISCUSSION}

The distinction between the two periods was the requirement of bioavailability and/or bioequivalence

Table. Medicine procurement by the Municipal Secretary of Health, Santa Catarina state, Southern Brazil, 2007-2008.

\begin{tabular}{lccccccc}
\hline Bidding processes & \multicolumn{3}{c}{2007} & \multicolumn{2}{c}{2008} \\
\hline Requirement of generic or innovator medicines & 1 & 2 & 3 & 1 & 2 & 3 & 4 \\
Number of items requested & No & No & No & Yes & Yes & No & No \\
Number of items procured & 189 & 6 & 1 & 195 & 109 & 28 & 12 \\
\% failed items & 184 & 6 & 1 & 84 & 78 & 21 & 12 \\
Number of complaints made by providers & 2.6 & 0.0 & 0.0 & 56.9 & 28.4 & 25.0 & 0.0 \\
\hline
\end{tabular}




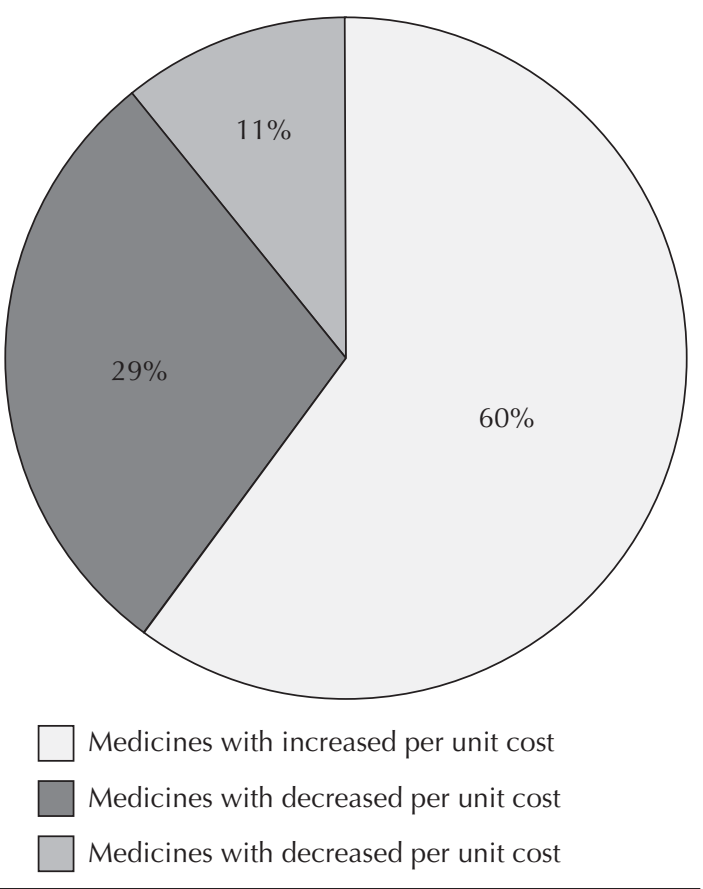

Figure 1. Change in per unit cost of medicines procured in 2008 by the Municipal Health Secretary, Santa Catarina, Southern Brazil, compared to 2007.

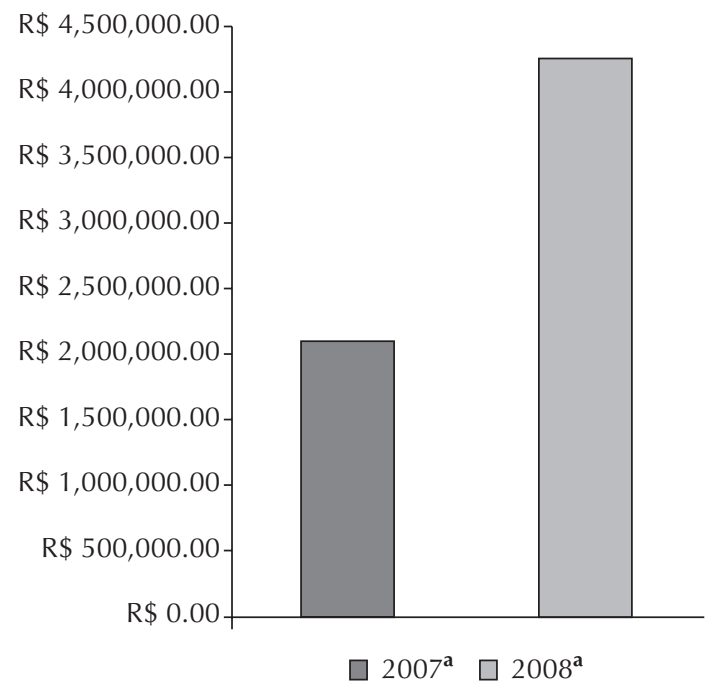

a 2007 (without requirement for bioavailability and or bioequivalence tests) and 2008 (with requirement for bioavailability and or bioequivalence tests)

Note: 2007 Values were adjusted by the General Price Index (IGP-DI) from the Getúlio Vargas Foundation.

Figure 2. Procurement of medicines according to average annual consumption and prices from auctions of medium size municipalities, Santa Catarina, 2007-2008.

tests. This requirement was responsible for differences in the number of procurement attempts, bidding processes, failed items, per unit cost and total value to procure the medicines.
The technical requirement to present the bioavailability and/or bioequivalence tests may be contested, which can make the process even slower, but does not disrespect the principles of public auctions. Due to the high percentage of failed items in the first and second bids of 2008, a third bidding process was necessary for which the bioavailability and/or bioequivalence tests were not required due to the possibility of stock-outs in the health system.

The amount of time to finalize the auction process was the same in both years. Although, in 2007, approximately $98 \%$ of items obtained price registration in the first auction process, while approximately $25 \%$ of items in 2008 only were price registered during the last auction process. An increased number of items in the first auction process is important to guarantee the supply of medicines, avoiding stock-outs in health units. The number of items missing and the duration of stock-out could not be estimated, since they are not registered in the system to manage supply.

The selection of the municipal medicines report was based on the Relação Nacional de Medicamentos Essenciais (RENAME - National List of Essential Medicines), with $70 \%$ of items standardized in the list. Nonetheless, the lack of quotes for generic medication in the auction process was notable and can be explained by the characteristics of the generics market. Despite the increase in production of generics in Brazil from 2.7 million units in June of 2000 to 200 million in December of 2005, as documented by Quental, ${ }^{12}$ a large part of this growth is due to spending on the innovator medicines.

According to Homedes, ${ }^{4}$ Brazil had 1,033 generic medications in 2005, a large amount in comparison to other Latin American countries. Nonetheless, Miranda ${ }^{11}$ highlights a lack of generic medicines on the list by RENAME. In the 2006 version of the essential medicines list, of the 330 pharmaceuticals in 522 formulations, $116(35.2 \%)$ in $210(40.2 \%)$ were generic medications; i.e., there were $214(64.9 \%)$ current components of RENAME for which there were no generic versions available in Brazil. ${ }^{11}$

According to Miranda et al, ${ }^{11}$ the National Medicines Policy guides the integration of access strategies, such as public production, generic policies, and essential medicines list. The medicines selected by RENAME address the priority health needs in the country and should constitute the base for generic production. ${ }^{10}$ Dialogue is needed between the Generic Medicines Policy and Pharmaceutical Services Policy, with incentives for the production of RENAME medications. The Generic Medications Policy should overcome two key limitations of the health industrial complex: the local entrepreneurial base for innovation and dedication to the health conditions of the Brazilian population. ${ }^{12}$ 
The difference between the unit price of medicines procured in 2007 and 2008 is significant. Even though 44 items had decreased costs, the overall impact of requiring the bioavailability and/or bioequivalence tests in procurement was an increase of more than two million reais in 2008 for the municipality. The increase is related to the fact that generic medicines are usually cheaper than the innovator medicines but, in most cases, more expensive to the brand name similar medicines.

Generic medicines tend to be cheaper than the innovator medicines, in large part, because they do not consider the costs of development and clinical trials. Another factor that contributes to the cheaper price of the generic is the lower investment in marketing to increase brand recognition. ${ }^{7}$

In Brazil, a study ${ }^{16}$ demonstrated that generics were introduced with prices $40 \%$ lower on average than the innovator medicine, with a trend towards increases differences over time. The demand for generic medicines has not caused a reduction in prices of the majority of innovator medicines. A similar result was described in Canada. ${ }^{7}$ This suggests that market loss to generics was insufficient to force an approximation in prices. ${ }^{16}$

Although generics policy is highlighted as a way to reduce prices, this is only true if comparing generics and the innovator medicines. Brand name similar medicines are sold in Brazil for lower prices than generics, especially in public auctions, so that generics are uncompetitive in terms of price. Since the auctions are decided by the lowest price, the cost of medicines explains the low percentage of generics available in the public sector.

Analysis of the auction processes to procure medicines during the study period did not allow for estimation of the proportion of innovator, generic and brand name similar medicines procured in 2007. This is because the processes used the $\mathrm{BNN}$, and there is no record of the manufacturing laboratory and the commercial name of the medication in the official record, which are only available in the proposal by the company The information system to manage stocks also does not have this information available.

The production of two public edicts with different specifications may reduce the financial impact caused by procurement of generic medications without interfering in the quality of the procured medicines. Bioavailability tests are necessary for solid and oral suspension medicines, be they generic or innovator medicines. For parenteral and oral solution medicines, this requirement is not necessary, as long as the dilution profile does not significantly interfere with the therapeutic result. If this strategy was adopted by the municipality studied, approximately $10 \%$ of the increased costs could be avoided by the municipality (about R $\$ 400,000$ ).

Generic medicines policy is an important component for the management of pharmaceutical services, but it is still removed from the reality of the public health system.

Tobar ${ }^{14}$ reports that the most radical strategy to increase the supply of generic products is to allow generics to be used for all products registered in the country, as Argentina did in 2002: generics and brand name similar medicines were leveled and could compete for price. In Brazil, the new legislation for brand name similar medicines and innovator medicines required them to have the same quality standards of generics. ${ }^{\text {b,c }}$ Perhaps this is the first step to incentivize price competitions between brand name similar medicines and generics and to increase their availability in public services.

In conclusion, municipal management adopted the policy to make medicines available that had presented bioavailability and bioequivalence tests to guarantee the provision of more effective and safe medications for the population. Nonetheless, procurement of these medicines had a large financial impact, with an increase of almost $100 \%$. Given finite financial resources for health, the implementation of new health policies should be rationally planned, based on technical criteria and evaluation of the financial impact from implementation.

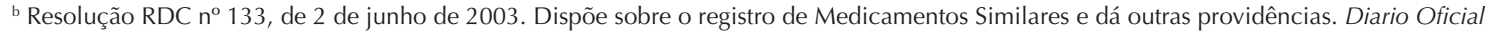
Uniao. 10 nov 1998;Seção 1:18-22.

c Resolução n 134, de 29 de maio de 2003. Dispõe sobre a adequação de produtos já registrados. Diario Oficial Uniao. 2 jun $2003 ;$ Seção 1:22.
} 


\section{REFERENCES}

1. Batistic MA, Auricchio MT, Markman BEO. Avaliação da qualidade de comprimidos revestidos e soluções orais de sulfato ferroso utilizados no tratamento da anemia ferropriva. Rev Inst Adolfo Lutz. 1998;57(1):25-8.

2. Bianchin MD, Blatt CR, Soares AS, Kulkamp IC. Avaliação da qualidade de comprimidos de propranolol e enalapril distribuídos no sistema público de saúde em uma cidade do sul do Brasil. Cienc Saude Colet. 2010. Disponível em: http://www.abrasco.org. br/cienciaesaudecoletiva/artigos/artigo_int.php?id_ artigo $=5130$

3. Dias CRC, Romano-Lieber NS. Processo da implantação da política de medicamentos genéricos no Brasil. Cad Saude Publica. 2006;22(8):1661-9. DOI:10.1590/S0102-311X2006000800014

4. Homedes N, Ugalde A. Multisource drug policies in Latin America: survey of 10 countries. Bull World Health Organ 2005;83(1):64-70. DOI: 10.1590/S004296862005000100016

5. King DR, Kanavos P. Encouraging the Use of generic medicines: implications for transition economies. Croat Med J. 2002;43(4):462-9.

6. Kornis GEM, Braga ML, Zaire CE. Os marcos legais das Políticas de Medicamentos no Brasil contemporâneo (1990-2006). Rev APS. 2008;11(1):85-99.

7. Lexchin J. The effect of generic competition on the price of brand-name drugs. Health Policy. 2004;68(1):47-54. DOI:10.1016/j.healthpol.2003.07.007

8. Luiza VL, De Castro CGSO, Nunes JM. Aquisição de medicamentos no setor público: o binômio qualidadecusto. Cad Saude Publica. 1999;15(4):769-76. DOI:10.1590/S0102-311X1999000400011

9. Marin N, Luiza VL, Osório de Castro CGS, Machado dos Santos S. Assistência Farmacêutica para gerentes municipais. Rio de Janeiro: Organização Mundial da Saúde, Organização Panamericana da Saúde; 2003.
10. Mendis S, Fukino K, Cameron A, Laing R, Filipe Jr A, Khatib O, Leowski J, Ewen M. The availability and affordability of selected essential medicines for chronic diseases in six low- and middle-income countries. Bull World Health Organ. 2007;85(4):279-288. DOI:10.2471/BLT.06.033647

11. Miranda ES, Pinto CBS, Reis, ALA, Emmerick ICM, Campos MR, Luiza VL, et al. Disponibilidade no setor público e preços no setor privado: um perfil de medicamentos genéricos em diferentes regiões do Brasil. Cad Saude Publica. 2009;25(10):2147-58 . DOI:10.1590/S0102-311X2009001000006

12. Quental C, Abreu JC, Bomtempo JV, Gadelha CAG. Medicamentos genéricos no Brasil: impactos das políticas públicas sobre a indústria nacional. Cienc Saude Coletiva. 2008;13(Suppl):619-28. DOI: 10.1590/S1413-81232008000700011

13. Rumel D, Nishioka AS, Santos AM. Intercambialidade de medicamentos: abordagem clínica e o ponto de vista do consumidor. Rev Saude Publica. 2006;40(5):921-7. DOI:10.1590/S003489102006000600024

14. Tobar F. Economía de los medicamentos genéricos en America Latina. Rev Panam Salud Publica. 2008;23(1):59-67. DOI:10.1590/S102049892008000100008

15. Vacca González CP, Fitzgerald JF, Bermúdez JAZ. Definición de medicamento genérico: ¿un fin o un medio? Análisis de la regulación en 14 países de la Región de las Américas. Rev Panam Salud Publica. 2006;20(5):314-23. DOI: 10.1590/S102049892006001000004

16. Vieira FP, Zucchi P. Diferenças de preços entre medicamentos genéricos e de referência no Brasil. Rev Saude Publica. 2006;40(3):444-9. DOI:10.1590/ S0034-89102006000300012

The authors declare that there are no conflicts of interest. 